\title{
Effects of Light Ethanol Consumption During Pregnancy: Increased Frequency of Minor Anomalies in the Newborn and Altered Contractility of Umbilical Cord Artery
}

\author{
MARÍA FLORENCIA IVELI, SILVINA MORALES, ALEJANDRO REBOLLEDO, VALERIA SAVIETTO, SILVIA SALEMME, \\ MARÍA APEZTEGUÍA, NORMA CECOTTI, RICARDO DRUT, AND VERÓNICA MILESI
}

Departamento de Ciencias Biológicas [M.F.I., A.R., V.S., S.S., V.M.], Departamento de Matemática [M.A.], Universidad Nacional de La Plata, La Plata 1900, Argentina; Instituto de Desarrollo e Investigaciones Pediátricas [M.F.I., S.M., N.C., R.D.], Hospital de Niños Superiora Sor María Ludovica, La Plata 1900, Argentina

\begin{abstract}
This study explores the effects of light maternal ethanol consumption during pregnancy on the appearance of minor malformations in neonates as well as on the contractile properties of their umbilical cord arteries (UCAs). Clinical external findings of newborns of women declaring light ethanol consumption during any period of their pregnancies [ethanol-exposed group (E group), $n=$ 79] were compared with those of nonexposed mothers [nonexposed to ethanol group (NE group), $n=100]$. Women who smoked or had any associated pathology were excluded. E group mothers consumed, on average, 200-250 mL ethanol/trimester (upper limit $700 \mathrm{~mL} /$ trimester). Sixty-six percent of the neonates in the $\mathrm{E}$ group presented at least one minor malformation (retromicrognathia and minor anomalies of the auricular/preauricular area were the more common), whereas only $16 \%$ of the NE group did $(p=0.0000)$. The percentage of children exhibiting Apgar scores $<7$ was significantly greater in the E group (11\% versus $2 \%, p=0.0119)$. UCAs from the E group developed significantly less contractile force $(p<0.05)$ than those of the NE group when exposed to $1 \mu \mathrm{M}$ serotonin (5-HT) or to a high $\mathrm{K}^{+}$depolarizing solution. This difference persisted after inhibition of endothelial release of nitric oxide (NO) and prostacyclin. In conclusion, even light drinking should be considered a risk during pregnancy. (Pediatr Res 61: 456-461, 2007)
\end{abstract}

$\mathrm{M}^{\mathrm{a}}$ aternal consumption of ethanol during pregnancy is associated with the appearance of fetal teratogenic effects such as growth restriction and mental impairments (1-3). Abnormal facial features including short palpebral fissures, microcephaly, smooth philtrum, thin upper lip, retrognathia, and auricular anomalies are also typical findings (3). Ethanol freely crosses the placenta and remains elevated in the amniotic fluid for several hours, even after being nondetectable in maternal blood $(4,5)$, meaning that the fetus is exposed to alcohol effects for a considerably longer time. Ethanol effects on the fetus are mainly related to gestational age at

Received August 2, 2006; accepted November 11, 2006.

Correspondence: Alejandro Rebolledo, Ph.D., Cátedra de Fisiología, Departamento de Ciencias Biológicas, Facultad de Ciencias Exactas, Universidad Nacional de La Plata., Calles 47 y 115, La Plata (1900), Argentina; e-mail: ar@biol.unlp.edu.ar

This work was supported by the grant BID 1201/0C-AR PICT No 5-14415 from the Agencia Nacional de Promoción Científica y Tecnológica (ANPCYT), and by a CONAPRIS scholarship from the Ministerio de Salud y Ambiente de la Nación, Argentina.

M.F.I. and S.M. contributed equally to this manuscript.

DOI: $10.1203 /$ pdr.0b013e3180332c59 which the exposure occurs, its amount, and individual susceptibility $(3,6)$. Jones and Smith $(7,8)$ defined and characterized the fetal alcohol syndrome (FAS) as the effects on newborns of chronic alcoholism during pregnancy. However, consumption of low doses of ethanol as well has been associated with partial expression of FAS. This was formerly known as fetal alcoholic effects (FAEs) $(9,10)$ and is now subdivided in three categories: partial FAS, alcohol-related birth defects (ARBDs), and alcohol-related neurodevelopmental disorders (ARNDs) (11). Full-blown FAS together with all its partial presentations are collectively referred to as fetal alcohol spectrum disorders (FASDs) (11). The incidence of full-blown FAS is variable, ranging from 0.5 to 3.0/1000 livebirths (12), whereas partial presentations seem to be many times more frequent $(13,14)$. Nevertheless, it is important to highlight that, to date, there is no consensus about which would be the maximum safe dose of ethanol that a woman may drink during pregnancy (2). For instance, as low as one drink per week has already been associated with adverse effects in the behavior of the offspring at age 6-7 y (15). Much has been written about full-blown FAS, but still there is scant information about its partial presentations, particularly regarding the consequences of in utero exposure to low levels of ethanol. Moreover, there are several potential confounding factors that should be taken into account when exploring ethanol effects on children, newborns, or fetal tissues, such as smoking, consumption of illicit drugs, or a family history of malformations. However, in many of the studies of the literature, these factors were not excluded for several reasons, e.g. unavailability of data in retrospective studies, failure to recognize them, impossibility to discard them, $(11,16-20)$. There are, however, some studies in which these factors have been taken into account $(15,21)$. Hence, one of the objectives of the present work was to evaluate the possibility that newborns of women who were light drinkers during pregnancy (a common and socially ac-

\footnotetext{
Abbreviations: 5-HT, serotonin; ARBDs, alcohol-related birth defects; ARND, alcohol-related neurodevelopmental disorder; E group, ethanol exposed group; FAEs, fetal alcoholic effects; FAS, fetal alcohol syndrome; FASDs, fetal alcohol spectrum disorders; high $\mathbf{K}^{+} \mathbf{K R B}$, high $\mathrm{KCl}$ solution; KRB, Krebs-Ringer bicarbonate solution; NE group, nonexposed to ethanol group; UCAs, umbilical cord arteries
} 
ceptable habit) already presented a higher risk of exhibiting malformations at birth, taking special care to eliminate confounding factors.

As well as affecting the fetus, ethanol may also interfere with maternal cardiovascular adaptations to pregnancy. For instance, alcohol-fed pregnant mice present impaired methacholine-induced vascular relaxation, a reaction that is normally mediated by NO release (22). This effect on blood vessels, which hinders the increase in maternal blood flow causing it to be insufficient for fetus metabolic requirements, may in part explain why alcohol consumption induces fetal damage and maternal disturbances.

Besides producing external phenotypic signs ethanol drinking along pregnancy may affect inner organs and systems of the fetus, a fact that is more difficult to evaluate at birth. In particular, ethanol exposure during embryogenesis can lead to vascular and cardiac abnormalities $(23,24)$. Hence, a second purpose of our investigation was to assess the possible effects of maternal ethanol consumption on the UCAs of the newborns, taking this vessel as a readily available sample of fetal vasculature and inferring that alterations of it may parallel those in other vessels. Additionally, because the main role of umbilical vessels is to transport blood between the fetus and the placenta participating in fetal nutrition and gas exchange, alcohol-induced damage to these vessels is interesting to report per se because it could alter fetal-placental blood flow leading to alterations in fetal growth.

\section{PATIENTS AND METHODS}

Sample and collection of data. The population used in this study consisted of a random sample of pregnant women who gave birth at the Maternity Service of the Hospital Interzonal General de Agudos "General San Martín" of La Plata, Argentina, from February 2005 to March 2006. The women were interviewed (45-60 min per interview) and asked for data using a questionnaire: name, age, marital status, educational level, history of abortions, medical control of pregnancy, weight gain during pregnancy, smoking habits, consumption of medication or illicit drugs, presence of a family history of malformations, existence of previous pathologies or development of one during pregnancy, and smoking and drinking patterns of their partners.

Regarding ethanol consumption, women were asked whether they had consumed during the first, second, or third trimester of pregnancy or during any combinations of these periods and the type of alcoholic beverage (beer, wine, whisky, etc) ingested during each period. They were also shown a group of glasses of different sizes and asked to refer the number and size of glasses they usually drunk (on a weekly basis) during each of the periods. With these data, taking into account the alcoholic content of each beverage, we estimated approximately the quantity of ethanol ingested by each woman and expressed it as milliliters of ethanol/trimester. Because we were interested only in the effects of light drinking, we set an upper limit. However, there is no consensus in the literature as to what should be considered light drinking. Suggestions are $<9 \mathrm{~mL} / \mathrm{d}(810 \mathrm{~mL} /$ trimester $)$ of ethanol (15) or fewer than three standard drinks per week (25), which would be approximately $6.5 \mathrm{~mL} / \mathrm{d}(585 \mathrm{~mL} /$ trimester) of ethanol, considering a content of $14.7 \mathrm{~mL}$ ( 0.5 fluid oz) of absolute ethanol in a standard drink (26). Taking into consideration these data, we set $700 \mathrm{~mL} /$ trimester as the highest limit to be considered a light drinker. Women who consumed more were eliminated from the E group. Women who were below the upper limit per trimester but presented single isolated episodes of heavy drinking were also excluded.

Additionally, we excluded from the study those mothers who smoked, consumed illicit drugs, were medicated (e.g. psychoactive drugs), or presented any pathology previous to the pregnancy or developed one during pregnancy, such as gestational diabetes or preeclampsia, or a family history of malformations.

The sample was finally arranged in two groups: one comprising women who had consumed alcoholic beverages during any of the three trimesters of pregnancy (E group), and another including the women who declared com- plete abstention during pregnancy and also during the 3 mo before conception (NE group).

Newborns whose mothers were included in the study were thoroughly examined twice, immediately after birth and $48 \mathrm{~h}$ later, to detect possible minor or major anomalies. The examination also included basic anthropometric measurements (e.g. weight, height, cephalic perimeter) and Apgar score (at $5 \mathrm{~min}$ ).

All the questionnaires and the examinations of the newborns were conducted by the same observer, author Silvina Morales, M.D., who is trained as a pediatrician and works in the Genetics Service of a children's hospital (Hospital de Niños Superiora Sor María Ludovica, La Plata, Argentina). Because the examination of the newborns and the collection of data from the mothers were performed by the same observer, it was not possible for her to ignore which of the babies were exposed in utero to ethanol and which were not. However, subjectivity was minimized because to determine the presence of a malformation, we followed established objective guidelines and measuring procedures currently in use at this Genetics Service, which are based on standard international textbooks $(27,28)$ and locally obtained data $(29)$. The Apgar score was determined by the pediatrician in charge of caring for the newborns.

Ethical considerations. The design of the questionnaire and the collection of the umbilical cords were approved by the ethics committee of the hospital where the samples were obtained, in accordance with the Declaration of Helsinki. Informed consent was obtained from the mothers before their inclusion in the study.

Tension measurements on intact tissue. For these experiments, only newborns delivered vaginally were included, excluding those born by cesarean section to avoid the possible interference of drugs used during this surgical procedure. Segments of nearly $10 \mathrm{~cm}$ coming from the middle section of each umbilical cord were cut and the morphology examined and taken to the laboratory in plastic vials containing a transport solution (in $\mathrm{mM}$ : 130 $\mathrm{NaCl}, 4.7 \mathrm{KCl}, 24 \mathrm{NaHCO}_{3}, 1.17 \mathrm{Na}_{2} \mathrm{HPO}_{4}, 1.16 \mathrm{MgSO}_{4}, 2.5 \mathrm{CaCl}_{2}$ ). UCAs were dissected from Wharton's jelly and cut in 2- to 3-mm rings. The rings were attached isometrically to a force transducer (Letica TRI-201) whose output signal was amplified and recorded using a data acquisition board (DT16EZ, Data Translation, Inc.) and software (Labtech Notebook Pro, Laboratory Technology Corp.) and stored for further analysis. The preparations were then submerged in a glass chamber containing Krebs-Ringer bicarbonate solution (KRB) continuously bubbled with a mixture of $5 \% \mathrm{CO}_{2}$ and $95 \% \mathrm{O}_{2}$ at $37^{\circ} \mathrm{C}$. The $\mathrm{KRB}$ composition was in $\mathrm{mM}: 130 \mathrm{NaCl}, 4.7 \mathrm{KCl}$, $24 \mathrm{NaHCO}_{3}, 1.17 \mathrm{Na}_{2} \mathrm{HPO}_{4}, 1.16 \mathrm{MgSO}_{4}, 2.5 \mathrm{CaCl}_{2}$, and 6.0 glucose. A tension of $2 \mathrm{~g}$ was applied, and the rings were allowed to equilibrate for 60 min, changing the solution in the chamber every $20 \mathrm{~min}$. After the stabilization period, the rings were induced to contract by exposure to $1 \mu \mathrm{M} 5$-HT or by depolarization with a high- $\mathrm{KCl}$ solution (high $\mathrm{K}^{+} \mathrm{KRB}$ ) (prepared by rising to $80 \mathrm{mM}$ the concentration of $\mathrm{KCl}$ in the $\mathrm{KRB}$ and lowering $\mathrm{NaCl}$ by the same amount to preserve the osmolarity). The force developed by the rings is expressed as gram force $(\mathrm{gF})$ per gram of wet tissue $(\mathrm{gW})$.

Histologic study. Transverse samples, $1 \mathrm{~cm}$ long, of the umbilical cord were $10 \%$ formalin fixed, paraffin embedded, and submitted to histologic study through hematoxylin and eosin-stained sections. Samples were coded for individualization without knowing the group of origin of the material.

Statistical treatment of data. The significance of associations between consumption of ethanol and minor malformations was assessed using $\chi^{2}$ and Fisher tests. A $p$ value of $\leq 0.05$ was taken to indicate statistical significance. The odds ratio (OR) with $95 \%$ confidence interval (CI) were calculated for statistically significance association.

The significance of the differences in other aspects of the two groups were evaluated using two independent sample $t$ and $\chi^{2}$ tests.

\section{RESULTS}

Characteristics of the mothers. A total of 324 mothers were interviewed, 121 of which were excluded because they presented possible confounding factors (see Patients and Methods section). Of the remaining mothers, 21 were excluded because they exceeded the upper limit to be considered light drinkers. We were then left with 100 in the NE group and 79 in the E group. The sample was homogeneous in all aspects apart from being or not being exposed to ethanol: there were no statistical differences between the $\mathrm{E}$ group and the NE group regarding geographic region of origin, age, marital status, educational level, history of abortions, medical control of the pregnancy, 
Table 1. Data obtained from the questionnaire answered by the mothers

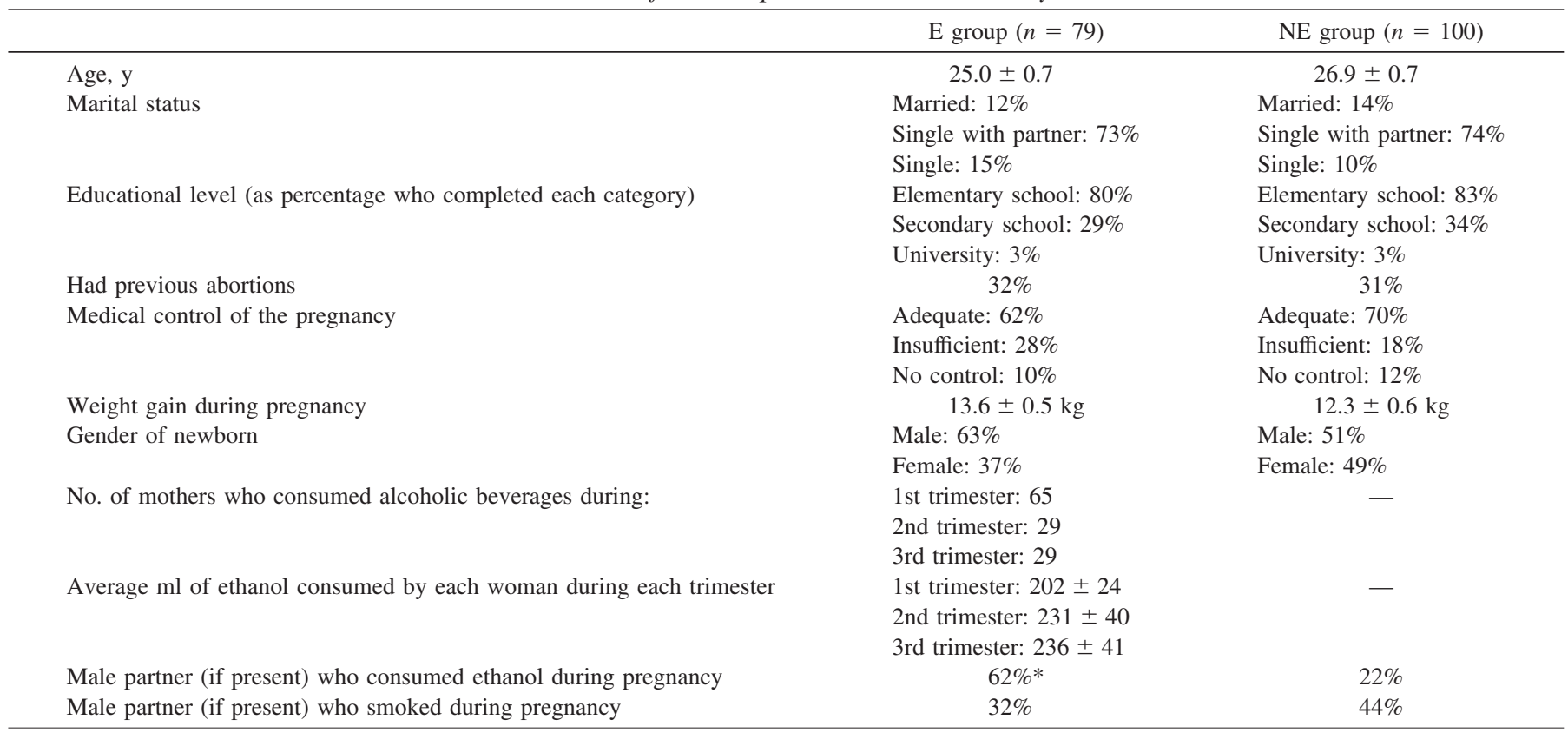

* Statistically different from the NE group: $p=0.0000, \mathrm{OR}=5.79, \mathrm{CI}: 3.00-11.16$.

weight gain during pregnancy, or gender of the newborns (Table 1). Due to the exclusion criteria adopted, none of the mothers of the E group consumed $>700 \mathrm{~mL}$ of ethanol during any of the 3-mo periods under consideration. Average values for each trimester are presented in Table 1.

Characteristics of the newborns. These are summarized in Table 2. There were no deaths at birth. Of the children, $75 \%$ were born by vaginal delivery, and $25 \%$ by cesarean section (no statistical differences between the $\mathrm{E}$ and $\mathrm{NE}$ groups). The children whose mothers were in the E group demonstrated (a) a statistically significant increase in the presence of minor anomalies (66\% in the E group versus $16 \%$ in the NE group), and (b) a significantly higher percentage of lower Apgar score at birth (11\% in the E group versus $2 \%$ in the NE group). The newborns did not differ in other characteristics, such as weight, length, or head circumference (Table 2).

Although other anomalies were found, facial anomalies were the most common minor malformations found in the group of newborns of E group mothers. Among them, there was a statistically significant increased frequency of retromicrognathia (Fig. 1), short nose, and minor anomalies of the auricular and preauricular area (Figs. $1 A$ and 2 ) such as low

Table 2. Features of the newborns

\begin{tabular}{lcc}
\hline \multicolumn{1}{c}{ Newborn } & $\begin{array}{c}\text { E group } \\
(n=79)\end{array}$ & $\begin{array}{c}\text { NE group } \\
(n=100)\end{array}$ \\
\hline Weight at birth, g & $3250 \pm 57$ & $3292 \pm 63$ \\
Length, cm & $48.9 \pm 0.3$ & $49.3 \pm 0.3$ \\
Head circumference, cm & $34.4 \pm 0.2$ & $34.1 \pm 0.2$ \\
Apgar score $<7$ at 5 min & $11 \% *$ & $2 \%$ \\
Presence of at least one type of & $66 \% \dagger$ & $16 \%$ \\
$\quad$ malformation & &
\end{tabular}

* Statistically different from the NE group: $p=0.0119, \mathrm{OR}=6.3, \mathrm{CI}$ : $1.32-30.06$

$\dagger$ Statistically different from the NE group, $p=0.0000, \mathrm{OR}=10.11, \mathrm{CI}$ : $4.98-20.54$. implantation of the ears, poorly developed helix, preauricular pits, and accessory tragus (Table 3 ).

There was no statistical differences among the average quantity of alcohol consumed by mothers in the E group whose newborns did not present any minor anomalies (27/79) from that of mothers of neonates with anomalies (52/79) (Table 4).

In a subgroup of the $\mathrm{E}$ group consisting of 36 mothers who consumed ethanol during the first trimester of pregnancy but who did not drink during the second or third trimester, $75 \%$ of the neonates presented at least one type of malformation $(p=$ $0.0000, \mathrm{OR}=15.75$, CI: 6.25-39.70), again with retromicrognathia $(n=6)$ and ear and preauricular anomalies $(n=31)$ being the most common findings. These newborns also presented a significantly higher percentage of low Apgar scores at birth (19\%) compared with the NE group ( $p=0.001$, OR $=$ 11.83, CI: 2.33-60.08). The parameters obtained from this subgroup of newborns were not statistically different from the whole E group. Analysis of newborns to mothers who did not drink during the first trimester but drank during the second or third trimester was not done due to the low number of cases (only eight) in this category.
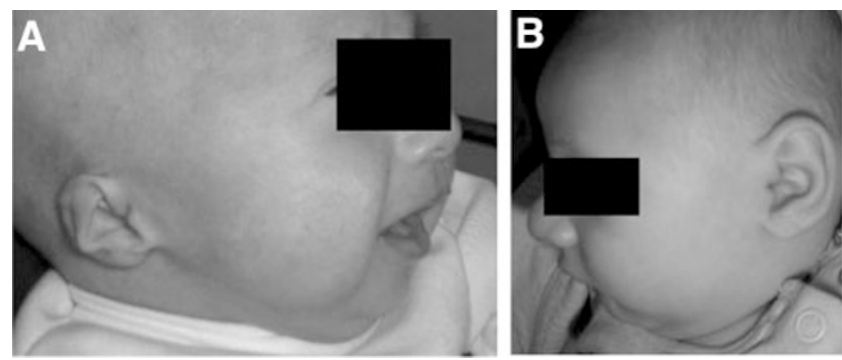

Figure 1. Typical examples of malformations in the newborns. (A) Newborn presenting retromicrognathia, low-set ears, and poorly developed helix. $(B)$ Newborn with retromicrognathia. Both newborns from the E group. 
A

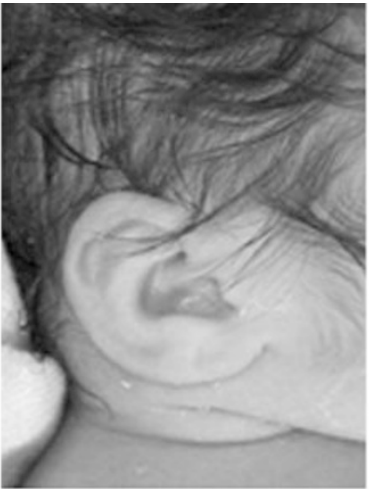

B
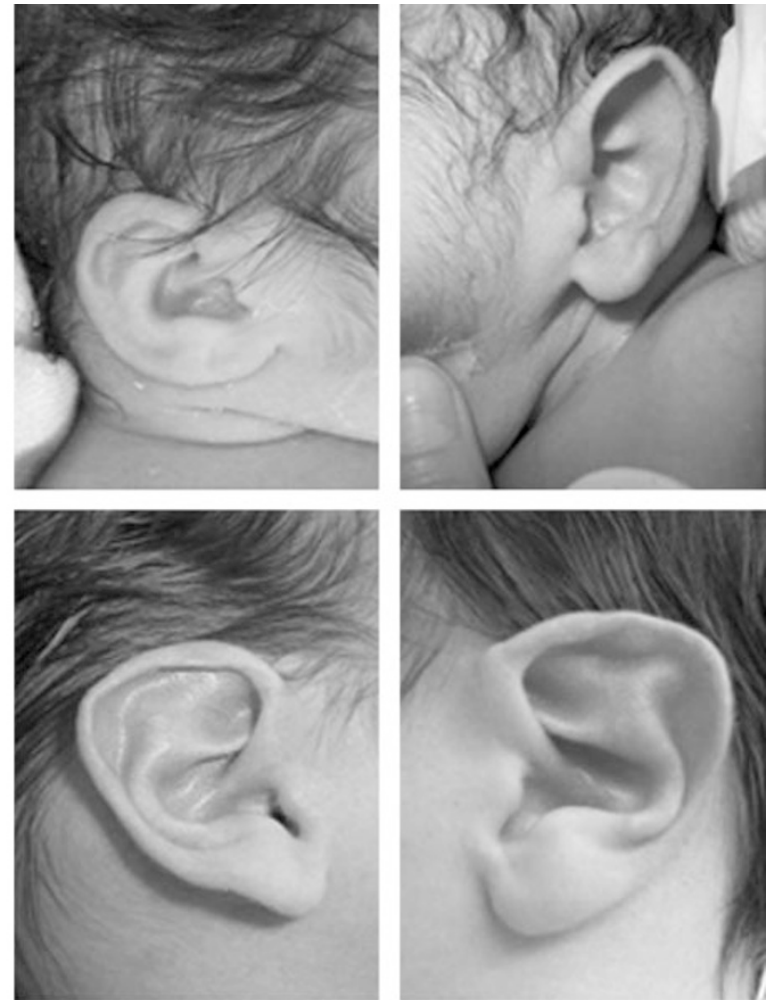

Figure 2. Typical examples of asymmetric ears in the newborns. $A, B$ : Newborns presenting asymmetric ears. Both from the E group.

Tension measurements on intact tissue. The UCA rings from the E group presented contractions that were significantly lower than those from the NE group (Fig. 3). To investigate whether endothelial products could be responsible for these observations, we repeated the experiments in the presence of $0.1 \mathrm{mM} \mathrm{N}$ (omega)-nitro-L-arginine methyl ester (L-NAME) and $10 \mu \mathrm{M}$ indomethacin, inhibitors of the release
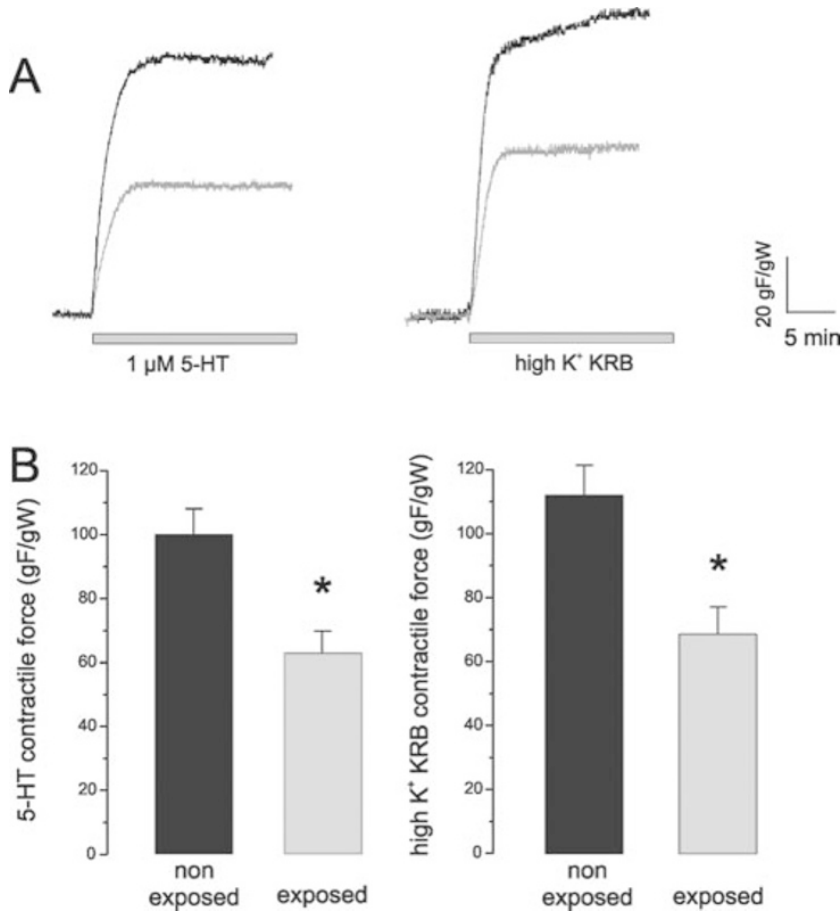

Figure 3. Force development in UCA rings. (A) Representative experimental tracings of force development induced by $1 \mu \mathrm{M}$ 5-HT (left) and high $\mathrm{K}^{+} \mathrm{KRB}$ (right) in UCA rings coming from newborns in the NE group (black tracings) or the E group (gray tracings). (B) Mean values of maximal force of experiments shown in A. 5-HT: $n=41$ for the NE group and $n=20$ for the E group. High $\mathrm{K}^{+} \mathrm{KRB}: n=31$ for the NE group and $n=26$ for the E group. *Statistically significant difference from the NE group $(p<0.05)$.

of NO and prostacyclin, respectively. Blockade of the production of these endothelial factors did not alter the results because UCA rings in the E group still developed less force than rings in the NE group when contracted with 5-HT (E group: $67.7 \pm 8.5 \mathrm{gF} / \mathrm{gW}, n=29$; versus $\mathrm{NE}: 97.2 \pm 8.2$,

Table 3. Minor facial anomalies found in the newborns*

\begin{tabular}{|c|c|c|c|c|}
\hline Type of facial anomaly & E group $(n=79)$ & NE group $(n=100)$ & $p$ & $\mathrm{OR}(\mathrm{CI})$ \\
\hline Short palpebral fissures & 5 & 2 & NS & \\
\hline Hypoplastic (smooth) philtrum & 2 & 0 & NS & \\
\hline Thin upper lip & 1 & 0 & $\mathrm{NS}$ & \\
\hline Cleft palate & 1 & 0 & NS & \\
\hline Retromicrognathia & 12 & 2 & 0.0011 & $8.78(1.90-40.48)$ \\
\hline \multicolumn{5}{|l|}{ Ear and preauricular anomalies } \\
\hline Total & 47 & 11 & 0.0000 & $13.22(5.98-29.21)$ \\
\hline Inclined ears & 6 & 0 & 0.0066 & $17.77(0.99-320.54)$ \\
\hline Large earlobes & 6 & 1 & 0.0450 & $8.14(0.96-69.06)$ \\
\hline Low set ears & 10 & 3 & 0.0134 & $4.69(1.24-17.66)$ \\
\hline Preauricular pits & 2 & 0 & NS & \\
\hline Poorly developed helix & 11 & 5 & 0.0377 & $3.07(1.02-9.25)$ \\
\hline Asymmetric ears & 9 & 1 & 0.0056 & $12.73(1.58-102.76)$ \\
\hline Accessory tragus & 3 & 1 & NS & \\
\hline Short nose & 4 & 0 & 0.0363 & $11.98(0.63-225.9)$ \\
\hline
\end{tabular}

* Many newborns presented more than one anomaly.

Table 4. Average amount of ethanol in milliliters consumed by some of the mothers in the E group as related to findings in the newborns

Average amount of ethanol (in $\mathrm{mL}$ ) consumed during each trimester by mothers whose newborns presented

No anomalies $(n=27)$

1st trimester

2nd trimester

3rd trimester

Any anomaly $(n=52)$

$200 \pm 40(n=22)$

$265 \pm 69(n=12)$

$233 \pm 66(n=11)$

$207 \pm 30(n=42)$

$207 \pm 49(n=17)$

$237 \pm 54(n=18)$ 
$n=39 ; p<0.05$ ) or high $\mathrm{K}^{+} \mathrm{KRB}$ (E group: $78.4 \pm 7.1$ $\mathrm{gF} / \mathrm{gW}, n=30$; versus $\mathrm{NE}$ group: $123.6 \pm 9.4 \mathrm{gF} / \mathrm{gW}, n=$ 33; $p<0.05)$.

Histologic findings. Microscopic observation of the histologic sections did not provide clear-cut evidence of the differences from one sample to the other, making it impossible to differentiate cases from the E group or NE group. Besides that, none of the cords presented any pathology as recognized by this examination.

\section{DISCUSSION}

Ethanol is a well-known fetal teratogen, and its consumption by pregnant women is associated with the development of FASDs. However, the threshold of ethanol consumption that results in harm to the fetus is not known, and, in particular, there are not a lot of data showing the effects of low doses of alcohol during pregnancy.

Our main objective was to study the effects of light drinking during pregnancy on newborns and their UCA; hence, excluded from the study were women who reported moderate or heavy ethanol consumption. Additionally, to avoid other confounding factors, we also excluded from this study mothers who smoked, consumed illicit drugs or prescription medications (e.g. psychoactive drugs), had preexisting or pregnancyrelated pathologies, and women with a family history of malformations.

One of the main findings regarding newborns of mothers in the E group is that the $66 \%$ of them presented at least one type of minor anomaly/malformation compared with the $16 \%$ in the NE sample, particularly retromicrognathia and ear/ preauricular anomalies. This is in accordance with the fact that cranial and facial malformations are the most common features of FASDs (2). It must be taken into account that in addition to inducing facial dysmorphism, ethanol can affect the development of neural structures, particularly the brain (30) and ocular system (31). In addition, neural damage may be present even in the cases in which the facial appearance can be considered normal (3). Hence, studies such as ours may be complemented with others in which children exposed in utero to ethanol that do not present abnormal facial features are reexamined later in life to explore possible subtle brain damage, such as cognitive or behavioral abnormalities $(15,32)$.

Studies done in primates (and also other species) showed that the craniofacial alterations associated with FASDs may result from exposure to ethanol at very early stages of embryogenesis (3), a period of time in which women may be still unaware that they are pregnant and hence do not consider changing habits or behaviors that may harm the conceptus. Our finding of $75 \%$ of newborns presenting at least one anomaly resulting from mothers who declared drinking only during the first trimester of pregnancy is in agreement with those data.

It is interesting to note, however, that the mean dose of ethanol reportedly consumed by women whose offspring did not present any anomaly was not significantly lower than that of mothers of newborns who exhibited at least one malformation. The depth and scope of present study do not allow further speculations on the causes of this finding, but reports in the literature point out that the effects of ethanol exposure on different persons may be modulated by many factors, among them, their genetic background (33).

Children born to mothers exposed to ethanol during pregnancy also had a higher probability of showing decreased vitality at birth, as evidenced by the results of the Apgar score. In a retrospective study, children diagnosed with FAS were found to have low Apgar scores at birth (34).

The mechanisms by which ethanol exerts its deleterious effects on the fetus include dose, time of the pregnancy during which the exposure occurs, and the specific organ or fetal system under consideration (35). It has been shown that in utero ethanol exposure can damage the cardiovascular system $(23,24)$. Hence, we examined its effects on umbilical arteries because these were the only readily available vessels of fetal origin and also because these arteries are fundamental in regulating fetoplacental blood flow. Histologic examination of hematoxylin and eosin-stained umbilical cord sections revealed no differences between samples coming from the $\mathrm{E}$ or NE group. However, we found that the umbilical arteries of newborns belonging to the $\mathrm{E}$ group presented a diminished contractile response to serotonin and to high extracellular $\mathrm{K}^{+}$. Changes in endothelial release of NO or prostacyclin are not involved in this effect because inhibition of their synthesis with L-NAME and indomethacin, respectively, did not alter the fact that the rings of the E group developed less force. In a study using rats, comparable results were reported by Turcotte et al. (36), who found that aortas of rats born to mothers exposed to ethanol during pregnancy presented lower responses to norepinephrine and high $\mathrm{K}^{+}$, in addition to lower vasorelaxation induced by an acetylcholine analogue. The fact that in human vessels we obtained results analogous to those derived from an animal model, in which prenatal ethanol exposure is produced in a controlled manner, gives additional support to our hypothesis that the observed results may be due to in utero ethanol effects on the cells of the UCA.

Finally, it is important to notice that none of the mothers included in the study can be termed alcoholic because the average amount of ethanol consumed was approximately 200-250 mL/ trimester, which in the literature is considered as light drinking. Consumption of these low doses of ethanol is socially accepted, and it is not frowned upon, but in the light of several studies $(4,15)$, as well as the present one, it should be considered an unnecessary and easily avoidable risk during pregnancy.

Therefore, the present report contributes to further characterize FASDs and reinforce the recommendations of health organizations proposing not only a decrease in consumption but instead total abstention from alcohol during pregnancy.

Acknowledgments. The authors thank Laura Rimorini for her excellent technical assistance.

\section{REFERENCES}

1. Abel EL, Sokol RJ 1986 Fetal alcohol syndrome is now leading cause of mental retardation. Lancet 2:1222

2. Eustace LW, Kang DH, Coombs D 2003 Fetal alcohol syndrome: a growing concern for health care professionals. J Obstet Gynecol Neonatal Nurs 32:215-221

3. Sulik KK 2005 Genesis of alcohol-induced craniofacial dysmorphism. Exp Biol Med 230:366-375 
4. Erskine RL, Ritchie JW 1986 The effect of maternal consumption of alcohol on human umbilical artery blood flow. Am J Obstet Gynecol 154:318-321

5. Ylikorkala O, Halmesmäki E, Viinikka L 1987 Effect of ethanol on thromboxane and prostacyclin synthesis by fetal platelets and umbilical artery. Life Sci 41:371-376

6. Stromland K, Pinazo-Duran MD 2002 Ophthalmic involvement in the fetal alcohol syndrome: clinical and animal model studies. Alcohol Alcohol 37:2-8

7. Jones KL, Smith DW 1973 Recognition of the fetal alcohol syndrome in early infancy. Lancet 2:999-1001

8. Jones KL, Smith DW 1975 The fetal alcohol syndrome. Teratology 12:1-10

9. Appelbaum MG 1995 Fetal alcohol syndrome: diagnosis, management, and prevention. Nurse Pract 20:24-34

10. Wolfgang LA 1997 Charting recent progress: advances in alcohol research. Alcohol Health Res World 21:277-286

11. Hoyme HE, May PA, Kalberg WO, Kodituwakku P, Gossage JP, Trujillo PM, Buckley DG, Miller JH, Aragon AS, Khaole N, Viljoen DL, Jones KL, Robinson LK 2005 A practical clinical approach to diagnosis of fetal alcohol spectrum disorders: clarification of the 1996 institute of medicine criteria. Pediatrics 115:39-47

12. Stratton KR, Howe CJ, Battaglia FC 1996 Fetal alcohol syndrome: diagnosis, epidemiology, prevention, and treatment. National Academy Press, Washington, DC pp 82-89

13. Sampson PD, Streissguth AP, Bookstein FL, Little RE, Clarren SK, Dehaene P, Hanson JW, Graham JM Jr 1997 Incidence of fetal alcohol syndrome and prevalence of alcohol-related neurodevelopmental disorder. Teratology 56:317-326

14. Young NK 1997 Effects of alcohol and other drugs on children. J Psychoactive Drugs 29:23-42

15. Sood B, Delaney-Black V, Covington C, Nordstrom-Klee B, Ager J, Templin T, Janisse J, Martier S, Sokol RJ 2001 Prenatal alcohol exposure and childhood behavior at age 6 to 7 years: I. dose-response effect. Pediatrics 108:E34

16. Miller LC, Chan W, Litvinova A, Rubin A, Comfort K, Tirella L, Cermak S, Morse B, Kovalev I 2006 Fetal alcohol spectrum disorders in children residing in Russian orphanages: a phenotypic survey. Alcohol Clin Exp Res 30:531-538

17. Viljoen DL, Gossage JP, Brooke L, Adnams CM, Jones KL, Robinson LK, Hoyme HE, Snell C, Khaole NC, Kodituwakku P, Asante KO, Findlay R, Quinton B, Marais AS, Kalberg WO, May PA 2005 Fetal alcohol syndrome epidemiology in a South African community: a second study of a very high prevalence area. J Stud Alcohol 66:593-604

18. Beblo S, Stark KD, Murthy M, Janisse J, Rockett H, Whitty JE, Buda-Abela M, Martier SS, Sokol RJ, Hannigan JH, Salem N Jr 2005 Effects of alcohol intake during pregnancy on docosahexaenoic acid and arachidonic acid in umbilical cord vessels of black women. Pediatrics 115:e194-e203

19. Naidoo S, Chikte U, Laubscher R, Lombard C 2005 Fetal alcohol syndrome: anthropometric and oral health status. J Contemp Dent Pract 6:101-115
20. Denkins YM, Woods J, Whitty JE, Hannigan JH, Martier SS, Sokol RJ, Salem N Jr 2000 Effects of gestational alcohol exposure on the fatty acid composition of umbilical cord serum in humans. Am J Clin Nutr 71:300S-306S

21. Jacobson SW, Chiodo LM, Sokol RJ, Jacobson JL 2002 Validity of maternal report of prenatal alcohol, cocaine, and smoking in relation to neurobehavioral outcome. Pediatrics 109:815-825

22. Cook JL, Zhang Y, Davidge ST 2001 Vascular function in alcohol-treated pregnant and nonpregnant mice. Am J Physiol Regul Integr Comp Physiol 281:R1449-R1455

23. Daft PA, Johnston MC, Sulik KK 1986 Abnormal heart and great vessel development following acute ethanol exposure in mice. Teratology 33:93-104

24. Fang TT, Bruyere HJ Jr, Kargas SA, Nishikawa T, Takagi Y, Gilbert EF 1987 Ethyl alcohol-induced cardiovascular malformations in the chick embryo. Teratology 35:95-103

25. Moore CA, Khoury MJ, Liu Y 1997 Does light-to-moderate alcohol consumption during pregnancy increase the risk for renal anomalies among offspring? Pediatrics 99:E11

26. Loock C, Conry J, Cook JL, Chudley AE, Rosales T 2005 Identifying fetal alcohol spectrum disorder in primary care. CMAJ 172:628-630

27. Gorlin RJ, Cohen MM, Levin LS 1990 Syndromes of the head and neck. Oxford University Press, Oxford, UK, pp 1220-1223

28. Goodman RM, Gorlin RJ 1983 The malformed infant and child: an illustrated guide. Oxford University Press, Oxford, UK, pp 430-437.

29. Oribe JA 1981 Cirugía maxilofacial. Lopez Libreros Editores, Buenos Aires, Argentina, pp 206-210.

30. Dunty WC Jr, Zucker RM, Sulik KK 2002 Hindbrain and cranial nerve dysmorphogenesis result from acute maternal ethanol administration. Dev Neurosci 24:328-342

31. Parnell SE, Dehart DB, Wills TA, Chen SY, Hodge CW, Besheer J, Waage-Baude HG, Charness ME, Sulik KK 2006 Maternal oral intake mouse model for fetal alcohol spectrum disorders: ocular defects as a measure of effect. Alcohol Clin Exp Res 30:1791-1798

32. Mattson SN, Riley EP, Gramling L, Delis DC, Jones KL 1998 Neuropsychological comparison of alcohol-exposed children with or without physical features of fetal alcohol syndrome. Neuropsychology 12:146-153

33. Cavieres MF, Smith SM 2000 Genetic and developmental modulation of cardiac deficits in prenatal alcohol exposure. Alcohol Clin Exp Res 24:102-109

34. Bagheri MM, Burd L, Martsolf JT, Klug MG 1998 Fetal alcohol syndrome: maternal and neonatal characteristics. J Perinat Med 26:263-269

35. Cudd TA 2005 Animal model systems for the study of alcohol teratology. Exp Biol Med 230:389-393

36. Turcotte LA, Aberle NS, Norby FL, Wang G-J, Ren J 2002 Influence of prenatal ethanol exposure on vascular contractile response in rat thoracic aorta. Alcohol 26:75-81 